
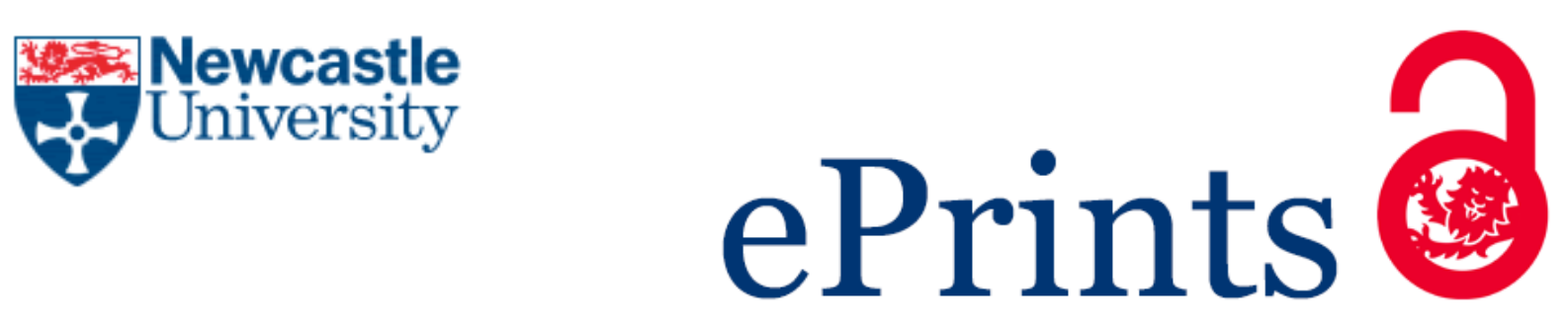

Currie CC, Stone SJ, Connolly J, Durham J.

Dental Pain in the Medical Emergency Department: A Cross-Sectional Study. Journal of Oral Rehabilitation 2016

DOI: http://dx.doi.org/10.1111/joor.12462

\title{
Copyright:
}

This is the peer reviewed version of the following article: Currie CC, Stone SJ, Connolly J, Durham J. Dental Pain in the Medical Emergency Department: A Cross-Sectional Study.Journal of Oral Rehabilitation 2016, which has been published in final form at http://dx.doi.org/10.1111/joor.12462. This article may be used for non-commercial purposes in accordance with Wiley Terms and Conditions for Self-Archiving.

DOI link to article:

http://dx.doi.org/10.1111/joor.12462

Date deposited:

$24 / 11 / 2016$

Embargo release date:

28 November 2017 


\section{Dental Pain in the Medical Emergency Department: A}

Cross-Sectional Study

Running Head: Dental Pain in ED

Article Category: Original Research

CC Currie $^{1}$, SJ Stone ${ }^{1}$, J Connolly ${ }^{2}$, J Durham ${ }^{3}$

\section{Affiliations}

1. Centre for Oral Health Research, School of Dental Sciences, Newcastle University, Framlington Place, Newcastle Upon Tyne NE2 4BW

2. Emergency Department, Royal Victoria Infirmary, Queen Victoria Road, Newcastle Upon Tyne NE1 4LP

3. Institute of Health and Society and Centre for Oral Health Research, Level 5, School of Dental Sciences, Newcastle University, Framlington Place, Newcastle Upon Tyne NE2 4BW

\section{Corresponding author}

Miss CC Currie

Centre for Oral Health Research

School of Dental Sciences

Newcastle University

Framlington Place

Newcastle Upon Tyne

NE2 4BW

Email: charlotte.currie@newcastle.ac.uk 


\section{Abstract}

Objective: To examine the number of patients attending a medical emergency department (MED) with dental problems over a three year period.

Design: A cross sectional study was carried out as part of a service evaluation. Data were collected via a database search of patient attendances at the MED using free text and the $10^{\text {th }}$ revision of the International Statistical Classification of Diseases and Related Health Problems (ICD-10) for oral and dental diagnoses. Data were analysed using descriptive statistics, T-Test, and chi-squared tests.

Results: Over the three-year period there were 2504 visits to the MED for dental related complaints, accounting for $0.7 \%$ of all attendances. The majority of patients were male $(53.9 \%)$, with a mean age of 29 (SD 19.4) years for men, and 32 (SD 19.7) years for females. The mean Index of Multiple Deprivation percent rank was $35.0 \%$. The most common diagnosis was unspecified dental disorder. Ten per cent of dental attendances to MED were repeat attendances by the same patients.

Conclusion: Patient attendances at MED for dental problems account for $0.7 \%$ of all attendances. The MED may not be the most appropriate place for these patients to attend, in terms of care pathways, and also for economic reasons. The reasons why patients attend MED for dental problems clearly warrant further research.

Keywords: dental pain, emergency department, toothache, service evaluation, care pathways 


\section{Introduction}

Almost one third of the adult population of the UK will only seek dental care when they are having an acute problem and $9 \%$ of the population experience ongoing dental pain ${ }^{1}$. Those seeking emergency dental care may seek care from other healthcare professionals such as general medical practitioners $(\mathrm{GPs})^{2,3}$,

pharmacists ${ }^{3}$, secondary care dental emergency clinics ${ }^{4}$, and medical emergency departments (MED) $)^{3,5,6}$ rather than attending with a general dental practitioner. According to Hospital Episode Statistics approximately $0.08 \%$ of visits to MEDs are for dental related problems in the $\mathrm{UK}^{7}$, however a much higher proportion is seen in the US (1.65\%), approximating to 2.1 million attendances per year. Ensuring that patients are treated in the most appropriate care settings, at the right time, by the right clinical team is essential for both the patient and the wider public not just to ensure appropriate diagnosis and treatment but also reduce unnecessary healthcare utilisation and cost. When patients attend MEDs for dental pain there is a reasonable possibility that someone who is not dentally qualified will examine and manage them, and therefore treatment may be limited to simply advice to go and see a dentist ${ }^{6}$, or the prescription of analgesia and or antibiotics ${ }^{8}$. If there is no definitive dental treatment carried out and the acute pain resolves, patients can then risk entering a cycle of repeat MED attendance once their pain recurs ${ }^{9}$.

Studies exploring MED attendances for dental pain are largely based in the US, with only two studies carried out in the UK in the 1990 s reported in the literature ${ }^{8,10}$. Major reforms of how dentistry is provided by the National Health Service (NHS) have taken place in the UK since these publications, which may have changed attendance patterns to MEDs, and MEDs are currently experiencing unprecedented demands in the UK so any unnecessary attendances simply add to this burden. The aim of this study was, therefore, to examine the number of patients attending an inner city major MED in the North East of England, over a three year period who were experiencing dental pain and did not require admission.

\section{Methods}

A cross sectional study was carried out as part of a service evaluation in the Newcastle upon Tyne Hospitals' NHS Foundation Trust, England. Anonymous data were collected via a database search of patient attendances at the MED (Royal Victoria Infirmary, Newcastle upon Tyne Hospitals NHS Foundation Trust), using free text and the $10^{\text {th }}$ revision of the International Statistical Classification of Diseases and Related Health Problems (ICD-10) for oral and dental diagnoses, over the period $1^{\text {st }}$ January 2013 to $31^{\text {st }}$ December 2015 . Patients who 
were admitted for treatment were excluded from the analysis as these patients most likely represented those whose attendance at the MED was definitively justified, as they required admission to the hospital for inpatient care. Those who were discharged from MED would most likely be suitable for treatment in primary care by a general dental practitioner instead of attending MED, as they did not require admission for treatment.

Data collected included age, gender and postcode allowing the calculation of the patient's index of multiple deprivation (IMD) ${ }^{11}$. For data analysis the IMD was converted to IMD deciles, as well as IMD rank by dividing the individual's postcode score by the total number of areas ranked. The lower the percentage rank (closer to $1 \%)$, the more deprived the area within England. Other data recorded included date of presentation, diagnosis, and outcome of MED attendance.

For comparison a further search was carried out for patients attending with diagnoses equating to "earache" or a "sore throat". These diagnoses were considered similar to dental pain in level of urgency for attending an MED.

Data were analysed in STATA release 12 (Stata Statistical Software, StataCorp LP, College Station, TX, USA) using descriptive statistics, T-Test, and chi-squared tests. 


\section{Results}

Over the three-year period there were 2821 visits to the MED registered for dental related complaints, accounting for $0.8 \%$ of all MED attendances. Once patients who were admitted for treatment were excluded from analysis, i.e. those requiring inpatient treatment (one or more night's stay in hospital) and therefore justified in their attendance to the MED, there were 2504 attendances (0.7\%). The data presented are for those who weren't admitted for treatment and were discharged from MED on the same day of their arrival, i.e. those patients who were assessed and considered suitable for discharge and therefore could have been managed in primary care.

The majority of patients were male (53.9\%), with a mean age of 29 (SD 19.4) years for men, and 32 (SD 19.7) years for females. The age range, IMD deciles and diagnoses of patients attending are shown in Figures 1 and 2 and Table 1 respectively. There was a significant difference in age of presentation between genders $(\mathrm{t}(2502)=3.0869, \mathrm{p}=0.002,95 \% \mathrm{Cl}$ difference $0.9,4.0$ years). The mean per cent IMD rank was $35.0 \%$ (SD 28.9\%). The most common diagnosis was "dental unspecified". Individuals most frequently presented on a Saturday (22\%, Table 2).

Ten per cent of dental attendances to MED were repeat attendances by the same patients (Supplementary appendix 1), one repeat attender had 60 visits over the 3 year period for temporomandibular joint dislocation who was excluded from the analysis as a sensitivity analysis showed them to be such an extreme outlier they significantly skewed the results. The majority of repeat attenders (63\%) presented twice in the three-year period. Males accounted for $56 \%$ of the repeat attenders, which was not statistically significant $\left(X^{2}(1, n=190) p=0.92\right)$. The mean age of repeat attenders was 34 (SD 18.5) years, with a significant difference between age for repeat and non-repeat attenders $(t(2502)=-2.76, p=0.006,95 \% \mathrm{Cl}$ difference $-7.02,-1.19)$. The majority of repeat attenders were from the most deprived areas (IMD percent rank 30.3\%, SD 25.0\%). The most common diagnoses for repeat attenders were "dental unspecified" (27.2\%), "toothache" (16.2\%) and "dental abscess" (16.2\%).

The number of patients attending with diagnoses related to earache or sore throat, in comparison to dental complaints, are shown in Table 3. 


\section{Discussion}

According to hospital episode statistics $0.08 \%$ of MED attendances nationally are for dental complaints ${ }^{7}$, however over a three year period at a hospital in the North East of England dental attendances accounted for $0.7 \%$ of patient encounters. This may indicate that attendances for dental problems at MED are a bigger problem in Newcastle and its catchment area than elsewhere in the UK. Alternatively it is possible that national data could be skewed or flawed by particular regional differences either in attendances, services provided, or even coding. Without studies of a similar nature being carried out elsewhere in the UK it is difficult to ascertain why this difference has been found. In addition to this the diagnostic coding system used in the MED uses free text input, therefore if a patient's diagnosis was entered as "abscess" rather than "dental abscess" their data would not have been captured. This means that the numbers quoted may be an underestimate of the actual number of people attending. Our study also illustrates the importance of using routinely collected service data to look for trends or phenomena that need further exploration as there is the potential for these data to be collected solely for various monitoring purposes and therefore their value in prompting further scientific enquiry may be lost.

The reason for the high number of attendances to MED with dental problems in this North-East hospital are unknown, but it may be related to problems accessing a dentist in this area, or inadequacies in signposting of services, or health literacy. In addition, given that this MED is a type 1 major trauma centre ${ }^{12}$ for the area, has a high turnover of patients and has a dental hospital next door to it, the percentage of dental attendances may be even higher in other MEDs. In the North East there is an on-call dentist available for out-of-hours emergency care, and in the dental hospital a walk-in dental emergency department is available during working hours, the reason why these patients opt to visit the MED rather than one of these services is unknown but clearly requires further research.

The majority of patients attending with dental problems were male, in the third or fourth decade of life (figure 1) and living in the more deprived areas of the UK. This demographic is in keeping with previous studies carried out in the $\mathrm{US}^{9,13-25}$, Canada $^{26,27}$, Australia $^{28}$ and Korea ${ }^{29}$. Interestingly, it is also this demographic who are known not to attend a dentist on a regular basis, and instead opt for emergency dental treatment ${ }^{4,30-34}$. The reason for the gender differences observed is unknown, however may relate to the nature of the diagnoses (for example fractured mandibles), or the population size. A difference in age was noted between 
genders, the reason for this and the typical patient profile attending the MED, and not attending a dentist regularly is unknown and may warrant further research.

Ten per cent of attendances at the MED were repeat attendances. This is likely to have a significant economic impact on wider society, however the scale of this is unknown. Repeat attenders tended to be in their twenties or thirties, and living in the more deprived areas, which is in keeping with previous studies ${ }^{35,36}$. Sun et $a l^{9}$ identified that most patients report returning to the MED in the US as the treatment provided is temporary, and they are unable to afford definitive treatment with a dentist, so when the pain returns they reattend at MED for palliative care in the form of analgesia ${ }^{9}$. This could partially explain the phenomenon we have observed in our data. If this is the case then there is the risk of a vicious circle developing where a patient attends at the MED, receives palliation, and then re-attends for further (MED) care thereby increasing the (economic) impact of the original complaint. This type of cycle also places the patient at risk of a severe odontogenic infection requiring inpatient treatment, the consequences of which can include mortality ${ }^{37}$. In comparison, should these patients attend a dentist rather than an MED they are more likely to receive an accurate diagnosis and definitive treatment for the problem, thereby reducing the risk to their health.

The reasons why patients attend MED for dental problems rather than a dentist are unknown and under researched. However reasons may include access ${ }^{8}$, financial barriers ${ }^{9}$ to dental treatment, dental anxiety (with patients preferring to see a medical doctor than a dentist) ${ }^{10}$ or issues within health literacy and signposting of services. The most common days for attendance were a Saturday and Sunday, and this may indicate difficulties in access of emergency dentistry over the weekend. One limitation of this study is that time of attendance was not recorded on the database, therefore we were unable to calculate the number of attendances during the week that were out of hours. The reason some patients attended may be that they were seeking dental care out of hours, this raises the question as to why they chose to attend the MED rather than contact the out of hours dentist, this may relate to problems with health literacy and clearly requires further research.

The most common diagnoses were unspecified dental disorders. This is in keeping with previous studies, and may highlight medical doctors' minimal training and uncertainty regarding diagnosis and treatment of dental problems $^{9,14,18-20,25,38}$. Again, this indicates that patients attending MED with dental problems may be inappropriate. Within the hospital studied there are dentists working on the maxillofacial department who are available for advice and referral of patients from MED, in other UK hospitals, however, there are often no 
dental staff available and treatment of these patients relies solely on the medical staff within the MED. Even when dental staff are available as part of a maxillofacial on call service they are limited in treatment they can provide in the MED due to the facilities available, again highlighting that attendance to an MED may be inappropriate.

Diagnoses captured included those of fractured mandibles, temporomandibular joint (TMJ) dislocation and bleeding dental sockets (table 1). As these patients were discharged on the same day they were included in our dataset, however could be considered appropriate attendances at the MED. They do however, account for a low percentage of attendances in comparison to unspecified diagnoses, dental abscess and toothache. If a patient attends the MED and is discharged on the same visit it raises the question of where these patients should be managed for initial presentation before specialist outpatient referral if required. The management of the bleeding dental socket should be within the remit of a primary care dental practitioner, and with the increasing move towards dental specialists working within primary care, it may be that some of these patients requiring outpatient management could be seen within primary care.

Dental attendances at MED are likely to create an economic burden on the NHS, with an average MED attendance costing $f 132^{39}$ with no charge to the patient, in comparison an emergency dental visit costs on average $f 25.61$, with the patient paying a band $4 \mathrm{f} 19.70$ charge towards this ${ }^{40}$. Therefore it is much less expensive for the NHS if patients attend the dentist with dental problems, rather than MED and will also relieve some of the pressure on already over-stretched MED services. This potential economic impact gives weight to our argument that further research needs to be to highlight how dental emergencies can be better signposted to appropriate emergency care. In this study the number of patients attending with dental problems was comparable to those attending with earache or a sore throat, which are medical conditions that may also be managed in primary medical care. A further potential comparator could have been sinusitis, being another condition commonly managed in primary care, the authors however did not use this due to the potential overlap with symptoms of acute dental pain. To try and combat these inappropriate attendance patterns campaigns such as the "Choose Better" campaign have been initiated ${ }^{41}$, one consideration may be to add dental attendances to the marketing used for these campaigns.

The reasons for dental patient attendance to MED requires further research as mentioned above. A study with a qualitative approach may be considered appropriate in order to understand not only the reasons but also in 
what context the decision of the patient is made ${ }^{42}$. In addition to the reasons for these attendances the economic impact is unknown. Therefore, economic analyses should be carried out, as well as further studies in different locations within the UK, and at varying types of MED, to establish if geographical location and unit type have an effect on the proportion of dental attendances seen. If reasons for these attendance patterns and their impact can be identified, using both quantitative and qualitative data, then changes may be possible to try and encourage attendance at more appropriate dental services, for example by development of an intervention or policy change.

\section{Conclusion}

Patient attendances in MED for dental problems account for $0.7 \%$ of all MED attendances. This may not be the most appropriate place for these patients to attend, in terms of health, care pathways, and also for economic reasons. The reasons why patients attend MEDs with dental problems clearly warrant further research.

\section{Acknowledgements}

J.D. is funded by the National Institute for Health Research (NIHR; Clinician Scientist Award NIHR-CS-011-003). C.C. is funded by the European Society of Endodontology Young Investigator's Award. The views expressed in this publication are those of the author(s) and not necessarily those of the National Health Service, the NIHR, or the Department of Health in the United Kingdom. The authors declare no potential conflicts of interest with respect to the authorship and/or publication of this article.

\section{References}

1 Steele J PN, Fuller E, Treasure E. Urgent Conditions - a report from the Adult Dental Health Survey 2009. 2011 [cited 2016 17/05/2016]; Available from: http://www.hscic.gov.uk/catalogue/PUB01086/adul-dent-heal-surv-summ-them-the3-2009-rep5.pdf Anderson R, Richmond S, Thomas DW. Patient presentation at medical practices with dental problems: An analysis of the 1996 General Practice Morbidity Database for Wales. Br Dent J. 1999;186(6):297-300. 

dental health practitioners in developed countries: A review of the literature. Comm Dent Health. 2014;31(4):224-33. Currie CC, Stone SJ, Durham J. Pain and problems: a prospective cross-sectional study of the impact of dental emergencies. J Oral Rehab. 2015;42(12):883-9. Cohen LA, Bonito AJ, Akin DR, Manski RJ, Macek MD, Edwards RR, et al. Toothache pain: A comparison of visits to physicians, emergency departments and dentists. J Am Dent Assoc. 2008;139(9):1205-16. Cohen LA, Bonito AJ, Eicheldinger C, Manski RJ, MacEk MD, Edwards RR, et al. Comparison of patient visits to emergency departments, physician offices, and dental offices for dental problems and injuries. J Public Health Dent. 2011;71(1):13-22. Health and Social Care Information Centre. Monthly Hospital Episode Statistics for Admitted Patient Care, Outpatients and Accident and Emergency Data - April 2014 to March 2015: Topic of Interest Hospital Dentistry; 2015 17/11/2015. Pennycook A, Makower R, Brewer A, Moulton C, Crawford R. The management of dental problems presenting to an accident and emergency department. J Royal Soc Med. 1993;86(12):702-3. Sun BC, Chi DL, Schwarz E, Milgrom P, Yagapen A, Malveau S, et al. Emergency department visits for nontraumatic dental problems: A mixed-methods study. Am J Public Health. 2015;105(5):947-55. Patel KK, Driscoll P. Dental knowledge of accident and emergency senior house officers. Emer Med J. 2002;19(6):539-41.

11 Department of Communities and Local Government. English indices of deprivation 2010. 2010 [cited 2016 17/05/2016]; Available from: https://www.gov.uk/government/uploads/system/uploads/attachment_data/file/6871/1871208.pdf

12 The King's Fund. What's going on in A\&E? The key questions answered. 2016 [cited 2016 19/05/2016]; Available from: http://www.kingsfund.org.uk/projects/urgent-emergency-care/urgentand-emergency-care-mythbusters

13 Elangovan S, Nalliah R, Allareddy V, Karimbux NY, Allareddy V. Outcomes in patients visiting hospital emergency departments in the United States because of periodontal conditions. J Periodontol. 2011;82(6):809-19. 

visits for dental care in Kansas City, Missouri, 2001-2006. Public Health Reports. 2011;126(2):210-9. Seu K HK, Moy E. Emergency Department Visits for Dental-Related Conditions, 2009. 2012. Allareddy V, Rampa S, Lee MK, Allareddy V, Nalliah RP. Hospital-based emergency department visits involving dental conditions: Profile and predictors of poor outcomes and resource utilization. J Am Dent Assoc. 2014;145(4):331-7. Walker A, Probst JC, Martin AB, Bellinger JD, Merchant A. Analysis of hospital-based emergency department visits for dental caries in the United States in 2008. J Public Health Dent. 2014;74(3):18894.

Darling BG, Singhal A, Kanellis MJ. Emergency department visits and revisits for nontraumatic dental conditions in lowa. J Public Health Dent. 2016;76(2):122-8.

Lewis C, Lynch $\mathrm{H}$, Johnston B. Dental complaints in emergency departments: A national perspective. Annals Emer Med. 2003;42(1):93-9.

Anderson L, Cherala S, Traore E, Martin NR. Utilization of Hospital Emergency Departments for nontraumatic dental care in New Hampshire, 2001-2008. J Comm Health. 2011;36(4):513-6.

Okunseri C, Okunseri E, Thorpe JM, Xiang Q, Szabo A. Patient characteristics and trends in nontraumatic dental condition visits to emergency departments in the United States. Clin Cosmet Investig Dent. 2012;4:1-7.

Wall T. Recent trends in dental emergency department visits in the United States - 1997/1998 to 2007/2008. J Public Health Dent. 2012;72(3):216-20.

3 American Dental Association. Dental-Related Emergency Department Visits on the Increase in the United States. 2013 [cited 2016 16/03/2016]; Available from:

http://www.ada.org/ /media/ADA/Science\%20and\%20Research/HPI/Files/HPIBrief_0513_1.pdf Pajewski NM, Okunseri C. Patterns of dental service utilization following nontraumatic dental condition visits to the emergency department in Wisconsin Medicaid. J Public Health Dent. $2014 ; 74(1): 34-41$

DeLia D, Lloyd K, Feldman CA, Cantor JC. Patterns of emergency department use for dental and oral health care: Implications for dental and medical care coordination. J Public Health Dent. 2016;76(1):18. 
Quiñonez C, Gibson D, Jokovic A, Locker D. Emergency department visits for dental care of nontraumatic origin. Comm Dent Oral Epidemiol. 2009;37(4):366-71.

Quiñonez C. Self-reported emergency room visits for dental problems. Int J Dent Hygiene. 2011;9(1):17-20.

Verma S, Chambers I. Dental emergencies presenting to a general hospital emergency department in Hobart, Australia. Aust Dent J. 2014;59(3):329-33.

Bae JH, Kim YK, Choi YH. Clinical characteristics of dental emergencies and prevalence of dental trauma at a university hospital emergency center in Korea. Dent Traumatol. 2011;27(5):374-8. Scully C. The pattern of patient attendance for emergency care in a British dental teaching hospital. Comm dent health. 1995;12(3):151-4.

1 Matthews R, Scully C, Porter K, Griffiths M. An analysis of conditions presenting to a dental hospital emergency clinic. Health Trends. 1992;24(4):126-8.

Thomas DW, Satterthwaite J, Absi EG, Shepherd JP. Trends in the referral and treatment of new patients at a free emergency dental clinic since 1989. Br Dent J. 1997;182(1):11-4.

Sayers M, Rowland H, Djemal S. Experiences in a dental emergency clinic. Eur J Prosthodont Rest Dent. $2004 ; 12(1): 5-8$.

Nayee S, Kutty S, Akintola D. Patient attendance at a UK dental hospital emergency clinic. Br Dent J. 2015 11/27/print;219(10):485-8.

O'Brien GM, Stein MD, Zierler S, Shapiro M, O'Sullivan P, Woolard R. Use of the ED as a regular source of care: Associated factors beyond lack of health insurance. Annals Emer Med. 1997;30(3):286-91. Lang T, Davido A, Diakité B, Agay E, Viel JF, Flicoteaux B. Using the hospital emergency department as a regular source of care. Eur J Epidemiol. 1997;13(2):223-8.

Thomas SJ, Hughes C, Atkinson C, Ness AR, Revington P. Is there an epidemic of admissions for surgical treatment of dental abscesses in the UK? Br Med J. 2008;336(7655):1219-20.

Davis EE, Deinard AS, Maïga EWH. Doctor, my tooth hurts: The costs of incomplete dental care in the emergency room. J Pub Health Dent. 2010;70(3):205-10.

Department of Health. Reference costs 2014-15. 2015 [cited 2016 23/05/2016]; Available from: https://www.gov.uk/government/uploads/system/uploads/attachment_data/file/477919/201415_Reference_costs_publication.pdf 
23/05/2016]; Available from: https://www.bda.org/dentists/policy-campaigns/research/workforcefinance/ddrb/Documents/state_of_general_dental_practice_november_2013.pdf

41 NHS Leicester Leicestershire and Rutland. You can choose better. 2016 [cited 2016 23/05/2016]; Available from: http://www.choosebetter.org.uk/

42 Denzin NK, Lincoln YS. Handbook of qualitative research. $2^{\text {nd }}$ ed. Sage Publications Inc. London 2000

Table 1: Diagnoses of patients attending medical emergency department with dental complaints (Total 2504 patients)

\begin{tabular}{|c|c|c|c|}
\hline & Male, n (\%) & Female, $\mathrm{n}(\%)$ & Total, n (\%) \\
\hline Dental Unspecified & $322(24)$ & 219 (19) & $541(22)$ \\
\hline Dental Abscess & $267(20)$ & $251(22)$ & $518(21)$ \\
\hline Toothache & $177(13)$ & $176(15)$ & $353(14)$ \\
\hline Fractured Mandible & $111(8)$ & $21(2)$ & $132(5)$ \\
\hline $\begin{array}{l}\text { Temporomandibular } \\
\text { Joint Dislocation }\end{array}$ & $27(2)$ & $87(8)$ & $114(5)$ \\
\hline Candidiasis & $49(4)$ & $54(5)$ & $103(4)$ \\
\hline Bleeding Socket & $53(4)$ & $45(4)$ & $98(4)$ \\
\hline Dry Socket & $32(2)$ & $66(6)$ & $98(4)$ \\
\hline Soft Tissue Injury & $47(3)$ & $35(3)$ & $82(3)$ \\
\hline $\begin{array}{l}\text { Post Extraction } \\
\text { Complications } \\
\text { Unspecified }\end{array}$ & $46(3)$ & $31(3)$ & 77 (3) \\
\hline Dental Trauma & $47(3)$ & $23(2)$ & $70(3)$ \\
\hline Broken Tooth & $39(3)$ & $30(3)$ & $69(3)$ \\
\hline $\begin{array}{l}\text { Temporomandibular } \\
\text { Disorder }\end{array}$ & $27(2)$ & $26(2)$ & $53(2)$ \\
\hline Teething & $31(2)$ & $17(1)$ & $48(2)$ \\
\hline
\end{tabular}




\begin{tabular}{|l|l|l|l|}
\hline Other $^{\mathrm{a}}$ & $76(6)$ & $72(6)$ & $148(6)$ \\
\hline Total & $1351(100)$ & $1153(100)$ & $2504(100)$ \\
\hline
\end{tabular}

Data are given as $n(\%)$.

${ }^{a}$ Other diagnoses included caries, gingivitis, foreign bodies, dental restoration problems, mobile teeth, salivary gland disease, pericoronitis, herpes simplex, request for free dental treatment, oral ulceration and osteonecrosis. 
Table 2: Day of attendance at the medical emergency department for patients with dental complaints not requiring in-patient treatment (total number of patients 2504)

\begin{tabular}{|l|l|l|}
\hline Day of Presentation & Frequency & Percentage \\
\hline Monday & 326 & 13.0 \\
\hline Tuesday & 287 & 11.5 \\
\hline Wednesday & 263 & 10.5 \\
\hline Thursday & 296 & 11.8 \\
\hline Friday & 320 & 12.8 \\
\hline Saturday & 542 & 21.7 \\
\hline Sunday & 470 & 18.8 \\
\hline Total & 2504 & 100.0 \\
\hline
\end{tabular}


Table 3: Number of attendances at the medical emergency department for patients with dental complaints not requiring in-patient treatment, in comparison to earache and sore throat attendances also not requiring inpatient treatment over the three year period

\begin{tabular}{|l|l|l|l|l|}
\hline Year & $\begin{array}{l}\text { Dental Complaint, } \mathbf{n} \\
(\%)\end{array}$ & Earache, $\mathbf{n}(\%)$ & Sore Throat, $\mathbf{n}(\%)$ & Total ED \\
& & & $\begin{array}{l}\text { Attendances, } \mathbf{n} \\
(\%)\end{array}$ \\
\hline $\mathbf{2 0 1 3}$ & $740(0.7)$ & $826(0.8)$ & $860(0.8)$ & 109070 \\
\hline $\mathbf{2 0 1 4}$ & $801(0.7)$ & $611(0.5)$ & $920(0.8)$ & 114548 \\
\hline $\mathbf{2 0 1 5}$ & $963(0.8)$ & $1046(0.9)$ & $1222(1.0)$ & 117963 \\
\hline Total & $2504(0.7)$ & $2483(0.7)$ & $3002(0.9)$ & 341581 \\
\hline
\end{tabular}

Age of patients attending the medical emergency department with dental complaints

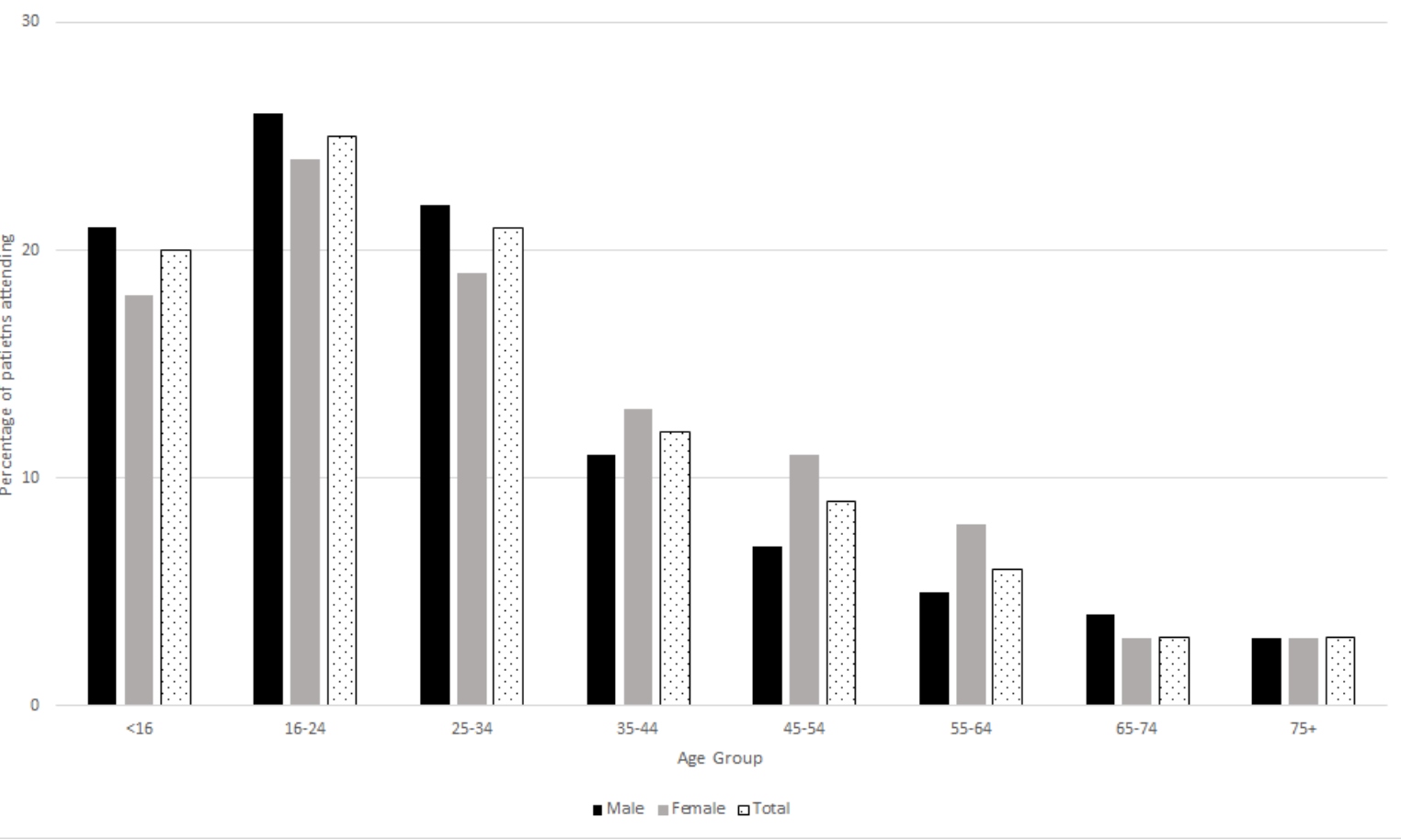


Figure 1: Age of patients attending the medical emergency department with dental complaints

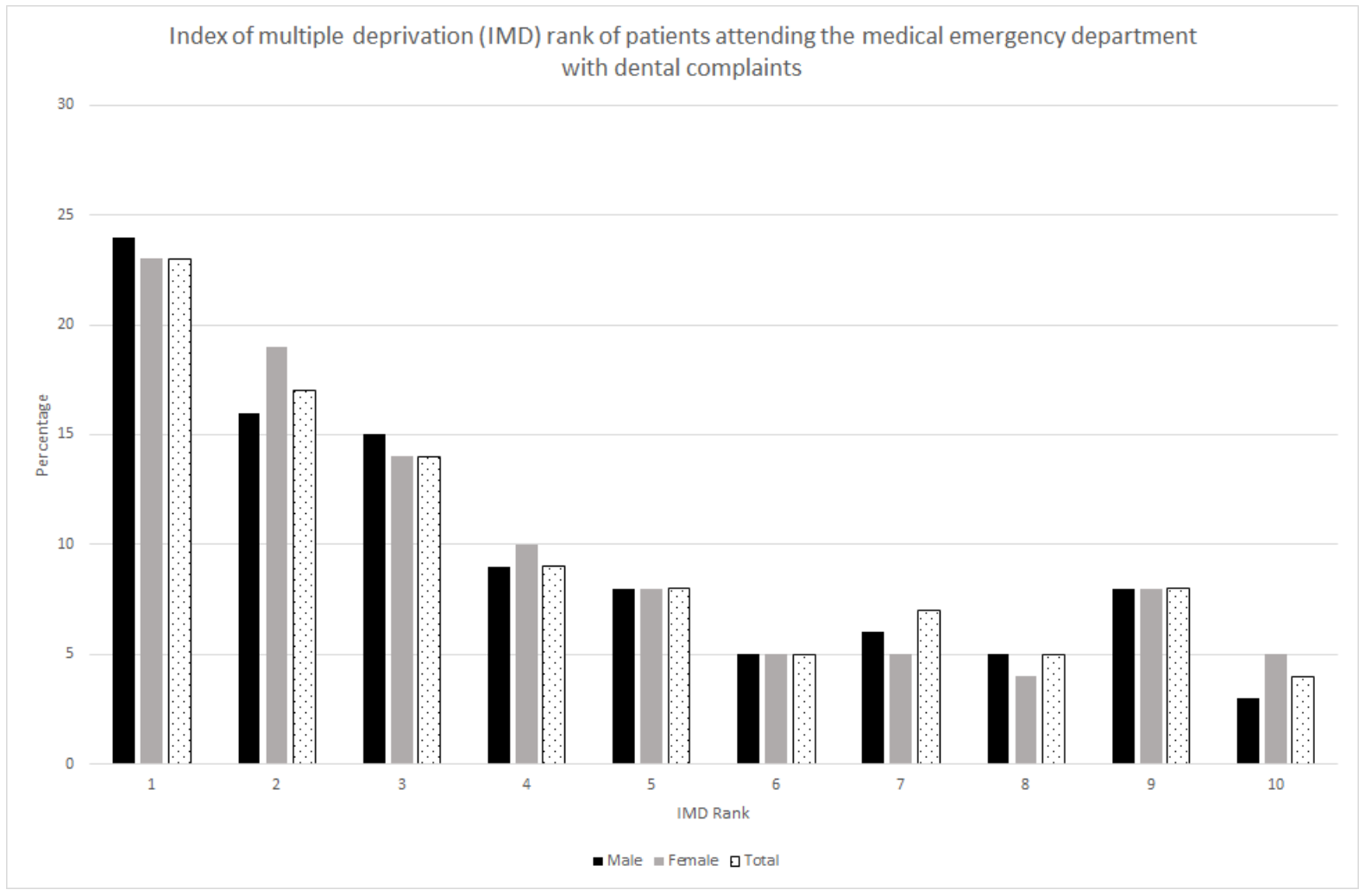

Figure 2: Index of multiple deprivation (IMD) rank of patients attending the medical emergency department with dental complaints (IMD rank is calculated using the 2010 English Census data, which defined 32, 482 small geographic areas in England. Each of these areas was assessed on 38 domains and scored according to standardised criteria. Each area was then ranked from worst score (rank 1) to best score (rank 10) according to IMD score (http://neighbourhood.statistics.gov.uk/dissemination/)

\section{Supplementary Online Data}

Supplemental Appendix 2: Sociodemographic details and diagnoses of patients attending medical emergency department with dental complaints

\begin{tabular}{|l|l|l|l|l|}
\hline & Male, $\mathbf{n}(\%)$ & Female, $\mathbf{n}(\%)$ & Total, $\mathrm{n}(\%)$ & Repeat Attenders, \\
n (\%)
\end{tabular}




\begin{tabular}{|c|c|c|c|c|}
\hline $25-34$ & $301(22)$ & $223(19)$ & $524(21)$ & $42(22)$ \\
\hline $35-44$ & $153(11)$ & $150(13)$ & $303(12)$ & $27(14)$ \\
\hline $45-54$ & $101(7)$ & $130(11)$ & $231(9)$ & $21(11)$ \\
\hline $55-64$ & $71(5)$ & $91(8)$ & $162(6)$ & $16(8)$ \\
\hline $65-74$ & $49(4)$ & $35(3)$ & $84(3)$ & $12(6)$ \\
\hline $75+$ & $40(3)$ & 39 (3) & 79 (3) & $4(2)$ \\
\hline \multicolumn{5}{|l|}{ IMD Rank Decile ${ }^{a}$} \\
\hline $\begin{array}{l}1 \text { (most deprived } \\
\text { areas of UK) }\end{array}$ & $308(24)$ & $233(23)$ & $541(23)$ & $37(21)$ \\
\hline 2 & $213(16)$ & $193(19)$ & 406 (17) & $36(20)$ \\
\hline 3 & $191(15)$ & $143(14)$ & 334 (14) & $39(22)$ \\
\hline 4 & $122(9)$ & $99(10)$ & $221(9)$ & $19(11)$ \\
\hline 5 & $101(8)$ & $82(8)$ & $183(8)$ & $15(8)$ \\
\hline 6 & $66(5)$ & $55(5)$ & $121(5)$ & $5(3)$ \\
\hline 7 & $81(6)$ & $52(5)$ & $133(7)$ & $8(5)$ \\
\hline 8 & 66 (5) & $46(4)$ & $112(5)$ & $6(3)$ \\
\hline 9 & $102(8)$ & $79(8)$ & $181(8)$ & $7(4)$ \\
\hline $\begin{array}{l}10 \text { (least deprived } \\
\text { areas of UK) }\end{array}$ & $45(3)$ & $51(5)$ & $96(4)$ & $5(3)$ \\
\hline \multicolumn{5}{|l|}{ Diagnosis } \\
\hline Dental Unspecified & $322(24)$ & 219 (19) & $541(22)$ & $52(27)$ \\
\hline Dental Abscess & $267(20)$ & $251(22)$ & $518(21)$ & $31(16)$ \\
\hline Toothache & $177(13)$ & $176(15)$ & $353(14)$ & $31(16)$ \\
\hline Fractured Mandible & $111(8)$ & $21(2)$ & $132(5)$ & $9(3.73)$ \\
\hline TMJ Dislocation & $27(2)$ & $87(8)$ & $114(5)$ & $20(10)$ \\
\hline Candidiasis & 49 (4) & $54(5)$ & $103(4)$ & $1(<1)$ \\
\hline Bleeding Socket & $53(4)$ & $45(4)$ & $98(4)$ & $14(7)$ \\
\hline Dry Socket & $32(2)$ & $66(6)$ & $98(4)$ & $5(3)$ \\
\hline
\end{tabular}




\begin{tabular}{|l|l|l|l|l|}
\hline Soft Tissue Injury & $47(3)$ & $35(3)$ & $82(3)$ & $2(1)$ \\
\hline $\begin{array}{l}\text { Post Extraction } \\
\text { Unspecified }\end{array}$ & $46(3)$ & $31(3)$ & $77(3)$ & $3(2)$ \\
\hline Dental Trauma & $47(3)$ & $23(2)$ & $70(3)$ & $8(4)$ \\
\hline Broken Tooth & $39(3)$ & $30(3)$ & $69(3)$ & $1(<1)$ \\
\hline TMD & $27(2)$ & $26(2)$ & $53(2)$ & $7(4)$ \\
\hline Teething & $31(2)$ & $17(1)$ & $48(2)$ & $0(0)$ \\
\hline Other & $76(6)$ & $72(6)$ & $148(6)$ & $5(3)$ \\
\hline
\end{tabular}

Data are given as $n(\%)$.

a IMD rank is calculated using the 2010 English Census data, which defined 32, 482 small geographic areas in England. Each of these areas was assessed on 38 domains and scored according to standardised criteria. Each area was then ranked from worst score (rank 1) to best score (rank 10) according to IMD score (http://neighbourhood.statistics.gov.uk/dissemination/)

${ }^{b}$ Other diagnoses included caries, gingivitis, foreign bodies, dental restoration problems, mobile teeth, salivary gland disease, pericoronitis, herpes simplex, request for free dental treatment, oral ulceration and osteonecrosis. 